\title{
Meal frequency differentially alters postprandial triacylglycerol and insulin concentrations in obese women
}

\author{
Tim Heden ${ }^{1}$, Ying Liu ${ }^{1}$, Lauren Sims ${ }^{1}$, Adam T. Whaley-Connell ${ }^{2}$, Anand Chockalingam ${ }^{2}$, \\ Kevin C. Dellsperger ${ }^{2,3}$, and Jill A. Kanaley ${ }^{1}$ \\ ${ }^{1}$ Department of Nutrition and Exercise Physiology, University of Missouri, Columbia, MO 65211 \\ ${ }^{2}$ Harry S Truman VA Medical Center and the Department of Internal Medicine Division of \\ Nephrology and Hypertension, University of Missouri, Columbia, MO 65211 \\ ${ }^{3}$ Department of Medical Pharmacology and Physiology, University of Missouri, Columbia, MO \\ 65211
}

\begin{abstract}
The aim of this study was to compare postprandial lipemia, oxidative stress, antioxidant activity, and insulinemia between a three and six isocaloric high carbohydrate meal frequency pattern in obese women. In a counterbalanced order eight obese women completed two, $12 \mathrm{~h}$ conditions in which they consumed 1500 calories (14\% protein, $21 \%$ fat, and 65\% carbohydrate) either as three 500 calorie liquid meals every $4 \mathrm{~h}$ or six 250 calorie liquid meals every $2 \mathrm{~h}$. Blood samples were taken every $30 \mathrm{~min}$ and analyzed for triacylglycerol (TAG), total cholesterol, high-density lipoprotein cholesterol, low-density lipoprotein cholesterol, oxidized low-density lipoprotein cholesterol, myeloperoxidase, paraoxonase- 1 activity, and insulin. The TAG incremental area under the curve (iAUC) during the three meal condition $(321 \pm 129 \mathrm{mg} / \mathrm{dL} \cdot 12 \mathrm{~h})$ was significantly lower $(P=0.04)$ compared to the six meal condition $(481 \pm 155 \mathrm{mg} / \mathrm{dL} \cdot 12 \mathrm{~h})$. The insulin iAUC during the three meal condition $(5,549 \pm 1,007 \mathrm{pmol} / \mathrm{L} \cdot 12 \mathrm{~h})$ was significantly higher $(P=0.05)$ compared to the six meal condition $(4,230 \pm 757 \mathrm{pmol} / \mathrm{L} \cdot 12 \mathrm{~h})$. Meal frequency had no influence on the other biochemical variables. Collectively, a three and six isocaloric high carbohydrate meal frequency pattern differentially alters postprandial TAG and insulin concentrations but has no effect on postprandial cholesterol, oxidative stress, or antioxidant activity in obese women.
\end{abstract}

\section{Introduction}

Cardiovascular disease (CVD) is the leading cause of death in the U.S. and although CVD is a complex multi factorial disease, it is considered by some a postprandial phenomenon [1]. Obesity is an independent risk factor for (CVD) [2], which is partially attributed to abnormalities in postprandial triacylglycerol (TAG) metabolism [3]. Exaggerated and prolonged elevations in postprandial TAG concentrations directly contribute to both the

Users may view, print, copy, and download text and data-mine the content in such documents, for the purposes of academic research, subject always to the full Conditions of use:http://www.nature.com/authors/editorial_policies/license.html\#terms

Address correspondence to: Jill A. Kanaley, PhD, 217 Gwynn Hall, Columbia, MO 65211, 573.882.2519, kanaleyj@ missouri.edu.

Disclosure

We have no conflicts of interest to declare. 
atherosclerotic [4] and thrombotic [5] processes of CVD. In addition, exaggerated postprandial TAG concentrations result in decreased plasma high-density lipoprotein cholesterol (HDL-C) concentrations [6-8]. As low HDL-C concentrations are a risk factor for CVD [9], the postprandial decrease in HDL-C concentrations may contribute to the enhanced CVD risk associated with abnormally elevated postprandial TAG in obese individuals [10].

In addition to abnormal postprandial lipid metabolism, an imbalance in redox status resulting in the overproduction of reactive oxygen and nitrogen species in addition to reduced antioxidant activity plays a role in the atherosclerotic process. In particular, the oxidative conversion of low-density lipoprotein cholesterol (LDL-C) to oxidized LDL-C (oxLDL-C) is a key event in the pathogenesis of CVD, and high oxLDL-C concentrations are a strong predictor of acute coronary heart disease events [11]. Myeloperoxidase (MPO) is a peroxidase enzyme that is positively associated with endothelial dysfunction [12], an early event in the pathogenesis of CVD [13]. The MPO generated nitrating oxidants play a role in the oxidative conversion of LDL-C into oxLDL-C [14]. Furthermore, MPO generated nitrating oxidants render HDL-C dysfunctional by binding to the apolipoprotein (apo) AI of HDL-C particles [15], thereby reducing the binding of apo AI with the antioxidant protein paraoxonase-1 (PON-1), the principal determinant of the antioxidant capacity of HDL-C [16]. As obesity inflicts one third of the U.S. population, it is important that effective therapies be identified that can beneficially alter postprandial biomarkers associated with CVD in obese individuals.

The National Cholesterol Education Program Adult Treatment Panel III guidelines state dietary interventions should be the first line of treatment to reduce CVD risk [17]. One form of diet therapy often suggested to improve health is altering meal frequency. The current dogma among health care professionals and the lay press is that consumption of smaller, more frequent meals may reduce CVD risk more so than larger, less frequent meals. However, very few controlled studies are available to justify this claim. Some studies have assessed how meal frequency alters traditional fasting biomarkers associated with CVD. In one study, males consuming 17 small meals daily for two weeks reduced their fasting total cholesterol (TC), insulin, and c-peptide concentrations more so than consuming three daily meals [18]. In other controlled feeding studies lower fasting TC and fasting glucose concentrations occurred when normal-weight men and women consumed three meals compared to one meal per day for eight weeks $[19,20]$. These studies suggest increasing meal frequency may reduce CVD risk. However, not all studies suggest increasing meal frequency is beneficial. In a cross over study, 12 or three daily meals for two weeks did not alter fasting TAG, glucose, insulin, or TC concentrations in young women [21]. A limitation to the previous studies is that CVD risk was assessed using traditional fasting biomarkers associated with CVD. Given that CVD is considered by some a postprandial phenomenon, the impact of meal frequency on postprandial metabolism will provide important insight about how meal frequency may reduce CVD risk. However, very few controlled feeding studies have examined how meal frequency alters postprandial metabolism. Previous reports examining the acute effects of a three or six isocaloric meal frequency pattern have demonstrated higher postprandial insulin concentrations in normal-weight [22, 23] or overweight and obese [24] men and higher postprandial glucose concentrations in 
overweight and obese men [24] while consuming three meals compared to six isocaloric meals. On the contrary, higher glucose excursions were observed after six meals compared to three meals in normal-weight individuals [25]. Given the discrepancy in findings, it is difficult to ascertain which meal frequency, three or six meals, will improve postprandial metabolism more so to reduce CVD risk. Therefore, more research is warranted. To our knowledge, no research has compared the acute effects of a three and six isocaloric meal frequency pattern on other postprandial biomarkers associated with CVD including lipid concentrations, oxidative stress, or antioxidant activity in obese premenopausal women, a group at risk for CVD. Therefore, the specific purpose of this study was to compare postprandial lipemia (TAG, TC, LDL-C, and HDL-C), oxidative stress (oxLDL-C, MPO), antioxidant activity (PON-1), and insulinemia between a three and six isocaloric high carbohydrate meal frequency pattern in obese women, a group at risk for CVD. We hypothesized that the magnitude of change in postprandial responses would be less with the six meal frequency compared to the three meal frequency.

\section{Methods}

\section{Study Population}

The University of Missouri Institutional Review Board approved this study protocol and informed consent. All subjects provided written informed consent and were screened to determine eligibility. The screening included assessment of weight, height, waist and hip circumference, body composition, and fasting blood glucose. In addition, information about dietary intake, physical activity, and medical history were obtained via a self reported questionnaire. Inclusion criteria included obese women with a body mass index (BMI) $\geq 30$ $\mathrm{kg} / \mathrm{m}^{2}$, waist circumference $>88 \mathrm{~cm}$, body fat percentage $>35 \%$, normal fasting blood glucose concentration $(<100 \mathrm{mg} / \mathrm{dL})$, non tobacco users, sedentary lifestyle ( $<60 \mathrm{~min}$ of planned physical activity per week over the last 3 months), no prior history of heart, lung, kidney, endocrine, or liver disease, not currently taking any prescription medications known to alter glucose or lipid metabolism, pre menopausal, not pregnant or lactating, weight stable (weight change $\leq 3 \mathrm{~kg}$ over last 6 months), and not currently on a special diet (i.e. Atkins, etc.). Baseline lipid values ranged between $53-140 \mathrm{mg} / \mathrm{dL}$ for TAG, $139-224 \mathrm{mg} / \mathrm{dL}$ for TC, 36-61 mg/dL for HDL-C, and 75-151 mg/dL for LDL-C.

\section{Study Design}

In a randomized order and after a $12 \mathrm{~h}$ overnight fast with water ad libitum, the subjects completed two, $12 \mathrm{~h}$ conditions in which they consumed 1500 calories (Nutritional Shake, $14 \%$ protein, $21 \%$ fat, and $65 \%$ carbohydrate, Walgreens Co., Deerfield, IL, USA) either as three 500 calorie meals every $4 \mathrm{~h}$ or six 250 calorie meals every $2 \mathrm{~h}$ while remaining sedentary. There was a one month wash out period between conditions. Upon arrival for the $12 \mathrm{~h}$ study day, a certified nurse inserted a venous catheter into the antecubital vein of the subject. The catheter was kept patent with a saline drip. Venous blood samples were taken from a stopcock at baseline and every $30 \mathrm{~min}$ thereafter for $12 \mathrm{~h}$. Each blood sample (30 min) collected was analyzed for TAG and insulin concentrations. All other biochemical variables including TC, LDL-C, HDL-C, MPO, oxLDL-C, and PON-1 activity were measured at 0 (baseline) and the postprandial time points $2,4,6,8,10$, and $12 \mathrm{~h}$. In addition, 
the baseline sample was assayed for glucose concentration. Postprandial TAG and insulin concentrations change more rapidly and dramatically to meal ingestion compared to the other variables thus to more accurately observe postprandial TAG and insulin kinetics these variables were measured more frequently compared to all other variables.

\section{Anthropometric Measures}

Height and weight were measured using a digital scale and stadiometer. Waist (using belly button as anatomical reference) and hip circumference were taken with a measuring tape. The BOD POD® was used to determine body fat percentage, and the manufacturer's guidelines were followed (COSMED USA, Inc.). Prior to body fat testing, all participants avoided ingesting food or drink for $\sim 3 \mathrm{~h}$. All participants wore skintight clothing, a swim cap, and removed all jewelry and eyeglasses before testing. Lung volume was measured and body fat was estimated using the Siri equation.

\section{Dietary Assessment}

To control for the influence of dietary patterns on postprandial responses, the subjects kept a dietary record during the three days prior to each $12 \mathrm{~h}$ visit. A photocopy of this dietary record was given to each subject and they were asked to repeat the same dietary record prior to the subsequent visit. Dietary records were analyzed for total energy and macro/ micronutrient content using Food Processor SQL, version 10.8 (ESHA Research, Salem, OR, USA).

\section{Blood Handling and Analysis}

Venous blood samples $(\sim 3 \mathrm{~mL})$ were collected by syringes, transferred immediately into serum separator tubes, and separated by centrifugation at $3000 \mathrm{RPM}$ for $15 \mathrm{~min}$ at $4^{\circ} \mathrm{C}$. The serum was stored in cryogenic vials at $-80^{\circ} \mathrm{C}$ until analysis.

Serum TC, TAG, and glucose concentrations were determined by colorimetric assays (Fischer Scientific, Inc., Houston, TX, USA). The coefficient of variation (CV) for TC, TAG, and glucose was $2 \%, 1.5 \%$, and $1.8 \%$, respectively. A modified heparin- $\mathrm{MnCl}_{2}$ method, as previously described [26], was used to determine HDL-C concentrations, and the $\mathrm{CV}$ for this assay was $1 \%$. A modified Friedewald equation was used to determine serum LDL-C concentrations as this equation was shown to be the most accurate for determining postprandial LDL-C concentrations [27]. Serum insulin concentrations were determined using an Immulite 1000 Immunoassay System (Siemens Healthcare Diagnostics, Inc., Deerfield, IL, USA). The homeostatic model assessment of insulin resistance (HOMA-IR) and quantitative insulin sensitivity check index (QUICKI) were used to calculate insulin resistance and sensitivity, respectively, prior to each condition. Commercially available ELISA kits were used to determine MPO (Molecular Probes, Carlsbad, CA, USA) and oxLDL-C concentrations (ALPCO Diagnostics, Salem, NH, USA). The CV for MPO and oxLDL-C was $8 \%$ and $7.9 \%$, respectively. A commercially available assay kit was used to determine PON-1 activity (Molecular Probes, Carlsbad, CA, USA) and the CV for PON-1 was $7.9 \%$. 


\section{Statistical Analysis}

Statistical analyses were performed using Statistical Package for the Social Sciences (SPSS) statistical software, version 18.0 (SPSS Inc, Chicago, IL, USA). Postprandial responses between conditions were compared using the incremental area under the curve (iAUC), which was calculated using the trapezoidal method [28]. For the primary analysis, paired samples t-tests were used to compare the iAUC values between conditions for all variables. In addition, paired samples t-tests were used to compare HOMA-IR, QUICKI, and energy intake between conditions. For t-tests, Cohen's $d$ effect size $(d)$ was calculated using the formula $d=\left(M_{1}-M_{2}\right) / s_{p}$. The pooled standard deviation $\left(s_{p}\right)$ was used in the denominator because there was no control. For the secondary analysis, a mixed model (condition $\times$ time point) repeated measures ANOVA with Bonferroni post hoc tests was used to determine if statistical differences existed between the baseline and postprandial time points within and between each condition for all variables. For the ANOVA, the effect size was calculated in SPSS as partial eta squared $\left(\eta^{2}\right)$. Statistical significance was set at $P \leq 0.05$ and values are reported as means \pm s.e.m.

\section{Results}

\section{Subject Characteristics}

Eight obese women with an average age of $39 \pm 3$ y completed this study. The average BMI, waist circumference, hip circumference, and body fat percentage of the participants were $34.5 \pm 1.3 \mathrm{~kg} / \mathrm{m}^{2}, 100.6 \pm 3.7 \mathrm{~cm}, 121.5 \pm 3.5 \mathrm{~cm}$, and $46.5 \pm 2.2 \%$. Prior to each condition, baseline HOMA-IR (three meals $=1.75 \pm 0.13$ vs. six meals $=1.54 \pm 0.25, P=0.16$ ) and QUICKI (three meals $=0.35 \pm 0.01$ vs. six meals $=0.36 \pm 0.01, P=0.10$ ) were not significantly different between conditions.

\section{Diet}

Average daily energy intake during the three days prior to the three ( $2807 \pm 323$ calories) and six ( $2760 \pm 315$ calories) meal conditions were not significantly different $(P=0.86)$. In addition, no differences existed between average daily ingestion of the antioxidants Vitamin A, $\beta$-carotene, Vitamin $\mathrm{C}$, and Vitamin $\mathrm{E}$ during the three days prior to each condition. Subjects had a usual meal frequency of 3-4 meals per day.

\section{Postprandial Lipemia and Insulinemia}

Figure 1 and 2 shows the $12 \mathrm{~h}$ time course and iAUC for TAG and insulin, respectively, during both conditions. The TAG iAUC was significantly lower $(P=0.04, d=0.40)$ during the three meal condition $(321 \pm 129 \mathrm{mg} / \mathrm{dL} \cdot 12 \mathrm{~h})$ compared to the six meal condition ( $481 \pm$ $155 \mathrm{mg} / \mathrm{dL} \cdot 12 \mathrm{~h})$. In addition, there was a significant main effect of time $\left(P<0.01, \eta^{2}=\right.$ 0.23 ) and the post hoc tests revealed the TAG concentrations were significantly greater compared to baseline at time point $4.5,5,8.5$, and $9 \mathrm{~h}$ for the three meal condition and time point $4.5,5,6.5,7,10.5,11,11.5$, and $12 \mathrm{~h}$ for the six meal condition. There was no significant condition $\times$ time interaction for TAG. On average, TAG concentrations were $15 \%$ and $22 \%$ above baseline for the three and six meal conditions, respectively. The insulin iAUC was significantly higher $(P=0.05, d=0.52)$ during the three meal condition $(5,549 \pm$ 
$1,007 \mathrm{pmol} / \mathrm{L} \cdot 12 \mathrm{~h})$ compared to the six meal condition $(4,230 \pm 757 \mathrm{pmol} / \mathrm{L} \cdot 12 \mathrm{~h})$. In addition, there was a significant main effect of time $\left(P<0.01, \eta^{2}=0.48\right)$ and a significant condition $\times$ time interaction $\left(P=0.01, \eta^{2}=0.19\right)$. The post hoc comparisons revealed significant elevations in insulin above baseline concentrations during both conditions at most time points (Figure 2) and significantly higher insulin concentrations during the three meal condition at time points $5,5.5,6,9,9.5$, and $10 \mathrm{~h}$ compared to the six meal condition. On average, insulin concentrations were $396 \%$ and $292 \%$ above baseline for the three and six meal conditions, respectively.

Table 1 shows the $12 \mathrm{~h}$ time course and iAUC for TC, LDL-C, and HDL-C concentrations during both conditions. The iAUC for TC $(P=0.27)$, LDL-C $(P=0.62)$, and HDL-C $(P=$ 0.18 ) were not significantly different between conditions, but there was a significant main effect of time for TC $\left(P<0.01, \eta^{2}=0.39\right)$, LDL-C $\left(P<0.01, \eta^{2}=0.40\right)$, and HDL-C $(P<$ $0.01, \eta^{2}=0.47$ ). The post hoc comparisons revealed a significant reduction in TC, HDL-C, and LDL-C concentration at each time point after baseline with one exception; the HDL-C concentration at the $4 \mathrm{~h}$ time point during the six meal condition was not significantly different compared to baseline. There was no significant condition $\times$ time interaction for these variables.

\section{Postprandial Oxidative Stress and Antioxidant Activity}

The iAUC for MPO $(P=0.44)$, oxLDL-C $(P=0.86)$, and PON-1 activity $(P=0.46)$ was not significantly different between conditions (Table 1$)$. In addition, there was no significant main effect of time for MPO $(P=0.18)$ or PON-1 activity $(P=0.24)$. There was a significant main effect of time for oxLDL-C concentrations $\left(P=0.01, \eta^{2}=0.17\right)$. The post hoc comparisons revealed oxLDL-C concentrations were significantly reduced at the $10 \mathrm{~h}$ time point during the three meal condition and 4 and $8 \mathrm{~h}$ time points during the six meal condition. On average, MPO, oxLDL-C, and PON-1 activity decreased $\sim 39 \%, \sim 13 \%$, and $\sim 15 \%$, respectively. There was no significant condition $\times$ time interaction for these variables.

\section{Discussion}

The aim of this study was to determine how a three vs. six meal per day frequency alters postprandial lipemia, oxidative stress, antioxidant activity, and insulinemia in obese premenopausal women. The primary finding of this study was that a three meal per day frequency results in lower postprandial TAG concentrations and higher postprandial insulin concentrations compared to a six meal per day frequency. In addition, postprandial TC, HDL-C, LDL-C, oxidative stress, and antioxidant activity did not differ between a three or six meal frequency. Exaggerated and prolonged postprandial TAG concentrations contribute to both the atherosclerotic [4] and thrombotic [5] processes of CVD, thus the implications of these findings are that a reduced meal frequency might be a strategy to lower CVD risk by reducing daylong postprandial TAG concentrations.

One potential mechanism by which consuming three meals results in lower TAG concentrations compared to six isocaloric meals may be mediated by the different insulin responses. The present data demonstrated greater postprandial insulin concentrations when 
obese women consumed three liquid meals compared to six isocaloric liquid meals. Insulin stimulates adipose tissue lipoprotein lipase activity in humans [29,30], an enzyme that functions to hydrolyze TAG to non-esterified fatty acids and glycerol, and non-esterifid fatty acids are subsequently taken up by adipocytes and re-esterified into a TAG droplet for storage. Thus, the greater insulin concentrations induced by three meals may be increasing adipose tissue lipoprotein lipase activity to a greater extent, thus promoting greater postprandial TAG clearance.

The greater insulin responses were not due to differences in insulin resistance or sensitivity between conditions. Instead, this response may have been mediated by the different glucose responses. We do not report postprandial glucose data, but other work has demonstrated greater postprandial glucose concentrations in response to three meals compared to six isocaloric meals in overweight and obese men [24], and thus greater postprandial insulin concentrations with three meals compared to six isocaloric meals [22-24]. The greater daylong postprandial insulin concentrations with three meals compared with six isocaloric meals may be a phenomenon that occurs in overweight and obese individuals only. For instance, Holmstrup et al. [25] demonstrated similar postprandial insulin responses in healthy normal-weight individuals who ingested three and six isocaloric liquid meals but greater postprandial glucose concentrations with six meals compared to three meals. These data suggest that meal frequency may alter postprandial metabolism differently in normalweight and obese individuals. This topic has not been explored and warrants further investigation.

Previous research has demonstrated reductions in postprandial TC concentrations in healthy men with no differences between a three or six meal frequency [22]. Similarly, the present investigation demonstrates postprandial TC concentrations decline but meal frequency does not alter the magnitude of the decline. Further, the declines in postprandial TC concentrations observed here are a result of reductions in both postprandial HDL-C and LDL-C concentrations. Declines in HDL-C concentrations have been reported to occur after high fat meal ingestion in postmenopausal women [6], normal-weight men [8], and obese men [7]. Thus, the present study adds to the existing literature by demonstrating that high carbohydrate meals also result in postprandial declines in HDL-C concentrations in obese women, but meal frequency has little influence on the magnitude of the drop. The decrease in postprandial HDL-C concentrations may possibly be linked with the rise in postprandial TAG concentrations. Increased TAG concentrations increase the exchange of TAG and cholesterol ester via cholesterol ester transfer protein between TAG and HDL-C [31], and TAG enriched HDL-C enhances the clearance of HDL-C apolipoprotein AI, via hepatic lipase, from the circulation [32]. These declines in postprandial HDL-C concentrations may contribute to the increased risk of CVD observed in obese individuals [2, 9]. Interestingly, there was a simultaneous decline in postprandial LDL-C concentrations in the present study, but no effect of meal frequency. To our knowledge, this is the first study to demonstrate high carbohydrate meals reduce postprandial LDL-C concentrations in obese women. This decline in LDL-C concentrations is unlikely to protect against CVD as prior research has shown a fat rich meal reduces postprandial LDL-C concentrations in individuals with type 2 diabetes, yet this population is still at an elevated risk to develop CVD [33]. The mechanism by which postprandial LDL-C decreases is due to the rise in postprandial insulin 
concentrations. Insulin increases LDL-C receptor activity, which would result in increased LDL-C catabolism and thus reduced postprandial LDL-C concentrations [22].

In contrast to our hypothesis, meal frequency did not differentially alter postprandial oxidative stress (MPO and oxLDL-C). Postprandial MPO concentrations decreased during both conditions, but this decline was not significant. This decline, however, parallels a prior report where postprandial MPO concentrations declined after consecutive high fat or high carbohydrate meals in normal glucose tolerant women [34] and after an oral glucose tolerance test in obese children and adolescents [35]. It is unclear why postprandial MPO concentrations decrease, thus this topic warrants further investigation. The effect of meal ingestion on postprandial oxLDL-C concentrations is controversial. We demonstrated oxLDL-C concentrations decline in the postprandial period, while other work has demonstrated no change in postprandial oxLDL-C concentrations after an oral glucose tolerance test in normal glucose tolerant adults [36] and children and adolescents [35]. In individuals with clinically suspected CVD, oxLDL-C significantly increased $6 \mathrm{~h}$ after a fatty meal [37]. Similarly, oxLDL-C significantly increased after an oral glucose tolerance test in individuals with impaired glucose tolerance and type 2 diabetes [36]. The reason for the discrepancy in postprandial oxLDL-C responses between studies is not completely understood. One possible explanation may be the magnitude of postprandial lipemia in these varied populations. In the present study, the average peak postprandial TAG concentration was $123-128 \mathrm{mg} / \mathrm{dL}$ while it was $262 \mathrm{mg} / \mathrm{dL}$ in another study [37]. In addition, glycemic control may alter the magnitude of change in oxLDL-C concentrations. For instance, individuals with glucose intolerance experienced elevated postprandial oxLDL-C concentrations, while individuals with normal glucose tolerance did not experience any change in postprandial oxLDL-C concentrations [36]. Potentially, other factors that could contribute to the discrepancy in findings between studies include age, antioxidants in the meal, meal composition, food form, hemodilution, body composition, timing and frequency of blood sampling, or a combination of these factors.

In the present study, postprandial PON-1 activity did not significantly change over the course of the day during both meal frequencies. This finding contrasts previous work that has shown postprandial PON-1 activity decreases in individuals with and without diabetes ingesting a high fat or high carbohydrate meal $[16,38]$. The inactivation of PON-1 was proposed to occur by oxidation products [38] but we observed a decline in the oxidation product oxLDL-C. Therefore, the reduction in the oxidation products oxLDL-C may have prevented the inactivation of PON-1 activity and may partly explain why no significant changes in postprandial PON-1 activity were observed in the present study.

\section{Limitations}

Although this study was carefully controlled, there are limitations that are often seen in many human studies. First, this investigation utilized a small sample size of Caucasian, premenopausal middle-aged obese women; therefore, the extrapolation of these findings to other populations is uncertain. Second, we did not directly measure TAG turnover or lipoprotein lipase activity but measured circulating venous TAG concentrations. This makes it difficult to establish a direct causal relationship between the TAG and insulin 
concentrations. Third, the study participants ingested a relatively high carbohydrate liquid meal. Our rationale for using a liquid meal was to ensure that each participant could consume the meal in the same amount of time. This way, the confounding influence that speed of eating could have on the postprandial responses was avoided. Although liquid meals result in lower postprandial glucose and insulin responses compared to solid meals $[39,40]$, to our knowledge it has not been established how food form affects postprandial lipids, oxidative stress, or antioxidant activity. In addition, it is not clear how the composition of the meal (i.e. high fat vs. high carbohydrate) may alter postprandial excursions in response to different meal frequencies. Therefore, the generalization of these findings to the "real life" situation where people are eating solid food, possibly with more fat, is limited. Despite these limitations, this is the first study to examine how manipulating meal frequency alters postprandial lipemia, oxidative stress, and antioxidant activity in obese individuals. The data from this research has provided the groundwork for future research to determine if temporal alterations in meal frequency can reduce CVD risk.

In conclusion, the cardiovascular stress of postprandial lipemia and oxidative stress over the course of a single day may seem trivial; however, these daily insults over time may lead to CVD. Altering meal frequency may be a therapy to reduce the magnitude of these daily insults, which potentially will reduce CVD risk. The results from this study demonstrate that consuming three liquid meals throughout the day results in lower postprandial TAG concentrations compared to six isocaloric meals in obese premenopausal women. Therefore, it is plausible that a reduced meal frequency may reduce CVD risk. However, more research is needed in other high CVD risk populations with different meal compositions and with solid food before definitive conclusions can be made.

\section{Acknowledgments}

This study was supported by a NIH R21DK084467-01 grant. We would like to thank the nurses of the clinical research unit for helping with catheter insertion and monitoring the subjects. We would also like to thank Grace Meers for her help with the MPO and PON-1 assays and undergraduate and graduate students that helped with data collection.

\section{References}

1. Zilversmit D. Atherogenesis: a postprandial phenomenon. Circulation. 1979; 60(3):473-485. [PubMed: 222498]

2. Hubert HB, Feinleib M, McNamara PM, Castelli WP. Obesity as an independent risk factor for cardiovascular disease: a 26-year follow-up of participants in the Framingham Heart Study. Circulation. 1983; 67(5):968-977. [PubMed: 6219830]

3. Potts JL, Coppack SW, Fisher RM, Humphreys SM, Gibbons GF, Frayn KN. Impaired postprandial clearance of triacylglycerol-rich lipoproteins in adipose tissue in obese subjects. Am J Physiol. 1995; 268(4 Pt 1):E588-594. [PubMed: 7733256]

4. Mamo JC, Proctor SD, Smith D. Retention of chylomicron remnants by arterial tissue; importance of an efficient clearance mechanism from plasma. Atherosclerosis. 1998; 141 (Suppl 1):S63-69. [PubMed: 9888645]

5. Lefevre M, Kris-Etherton PM, Zhao G, Tracy RP. Dietary fatty acids, hemostasis, and cardiovascular disease risk. J Am Diet Assoc. 2004; 104(3):410-419. quiz 492. [PubMed: 14993864]

6. Alssema M, El-Harchaoui K, Schindhelm RK, Diamant M, Nijpels G, Kostense PJ, Teerlink T, Heine RJ, Dallinga-Thie GM, Kuivenhoven JA, et al. Fasting cholesteryl ester transfer protein 
concentration is independently associated with the postprandial decrease in high-density lipoprotein cholesterol concentration after fat-rich meals: the Hoorn prandial study. Metabolism. 2010; 59(6): 854-860. [PubMed: 20005542]

7. Hajer GR, Dallinga-Thie GM, van Vark-van der Zee LC, Olijhoek JK, Visseren FL. Lipid-lowering therapy does not affect the postprandial drop in high density lipoprotein-cholesterol (HDL-c) plasma levels in obese men with metabolic syndrome: a randomized double blind crossover trial. Clin Endocrinol (Oxf). 2008; 69(6):870-877. [PubMed: 18394022]

8. De Bruin TW, Brouwer CB, Gimpel JA, Erkelens DW. Postprandial decrease in HDL cholesterol and HDL apo A-I in normal subjects in relation to triglyceride metabolism. Am J Physiol. 1991; 260(3 Pt 1):E492-498. [PubMed: 1900671]

9. Boden WE. High-density lipoprotein cholesterol as an independent risk factor in cardiovascular disease: assessing the data from Framingham to the Veterans Affairs High--Density Lipoprotein Intervention Trial. Am J Cardiol. 2000; 86(12A):19L-22L.

10. Bansal S, Buring JE, Rifai N, Mora S, Sacks FM, Ridker PM. Fasting compared with nonfasting triglycerides and risk of cardiovascular events in women. JAMA. 2007; 298(3):309-316. [PubMed: 17635891]

11. Meisinger C, Baumert J, Khuseyinova N, Loewel H, Koenig W. Plasma oxidized low-density lipoprotein, a strong predictor for acute coronary heart disease events in apparently healthy, middle-aged men from the general population. Circulation. 2005; 112(5):651-657. [PubMed: 16043640]

12. Vita JA, Brennan ML, Gokce N, Mann SA, Goormastic M, Shishehbor MH, Penn MS, Keaney JF Jr, Hazen SL. Serum myeloperoxidase levels independently predict endothelial dysfunction in humans. Circulation. 2004; 110(9):1134-1139. [PubMed: 15326065]

13. Halcox JP, Donald AE, Ellins E, Witte DR, Shipley MJ, Brunner EJ, Marmot MG, Deanfield JE. Endothelial function predicts progression of carotid intima-media thickness. Circulation. 2009; 119(7):1005-1012. [PubMed: 19204308]

14. Podrez EA, Schmitt D, Hoff HF, Hazen SL. Myeloperoxidase-generated reactive nitrogen species convert LDL into an atherogenic form in vitro. J Clin Invest. 1999; 103(11):1547-1560. [PubMed: 10359564]

15. Zheng L, Nukuna B, Brennan ML, Sun M, Goormastic M, Settle M, Schmitt D, Fu X, Thomson L, Fox PL, et al. Apolipoprotein A-I is a selective target for myeloperoxidase-catalyzed oxidation and functional impairment in subjects with cardiovascular disease. J Clin Invest. 2004; 114(4):529_ 541. [PubMed: 15314690]

16. Beer S, Moren X, Ruiz J, James RW. Postprandial modulation of serum paraoxonase activity and concentration in diabetic and non-diabetic subjects. Nutr Metab Cardiovasc Dis. 2006; 16(7):457465. [PubMed: 17015182]

17. Third Report of the National Cholesterol Education Program (NCEP) Expert Panel on Detection, Evaluation, and Treatment of High Blood Cholesterol in Adults (Adult Treatment Panel III) final report. Circulation. 2002; 106(25):3143-3421. [PubMed: 12485966]

18. Jenkins DJ, Wolever TM, Vuksan V, Brighenti F, Cunnane SC, Rao AV, Jenkins AL, Buckley G, Patten R, Singer W, et al. Nibbling versus gorging: metabolic advantages of increased meal frequency. N Engl J Med. 1989; 321(14):929-934. [PubMed: 2674713]

19. Stote KS, Baer DJ, Spears K, Paul DR, Harris GK, Rumpler WV, Strycula P, Najjar SS, Ferrucci $\mathrm{L}$, Ingram DK, et al. A controlled trial of reduced meal frequency without caloric restriction in healthy, normal-weight, middle-aged adults. Am J Clin Nutr. 2007; 85(4):981-988. [PubMed: 17413096]

20. Carlson O, Martin B, Stote KS, Golden E, Maudsley S, Najjar SS, Ferrucci L, Ingram DK, Longo DL, Rumpler WV, et al. Impact of reduced meal frequency without caloric restriction on glucose regulation in healthy, normal-weight middle-aged men and women. Metabolism. 2007; 56(12): 1729-1734. [PubMed: 17998028]

21. Murphy MC, Chapman C, Lovegrove JA, Isherwood SG, Morgan LM, Wright JW, Williams CM. Meal frequency; does it determine postprandial lipaemia? Eur J Clin Nutr. 1996; 50(8):491-497. [PubMed: 8863008] 
22. Jones PJ, Leitch CA, Pederson RA. Meal-frequency effects on plasma hormone concentrations and cholesterol synthesis in humans. Am J Clin Nutr. 1993; 57(6):868-874. [PubMed: 8503355]

23. Jones PJ, Namchuk GL, Pederson RA. Meal frequency influences circulating hormone levels but not lipogenesis rates in humans. Metabolism. 1995; 44(2):218-223. [PubMed: 7869919]

24. Leidy HJ, Armstrong CL, Tang M, Mattes RD, Campbell WW. The influence of higher protein intake and greater eating frequency on appetite control in overweight and obese men. Obesity (Silver Spring). 2010; 18(9):1725-1732. [PubMed: 20339363]

25. Holmstrup ME, Owens CM, Fairchild TJ, Kanaley JA. Effect of meal frequency on glucose and insulin excursions over the course of a day. The European e-Journal of Clinical Nutrition and Metabolism. 2010; 5(6):e277-e280.

26. Zhang JQ, Thomas TR, Ball SD. Effect of exercise timing on postprandial lipemia and HDL cholesterol subfractions. J Appl Physiol. 1998; 85(4):1516-1522. [PubMed: 9760349]

27. Puavilai W, Laorugpongse D, Deerochanawong C, Muthapongthavorn N, Srilert P. The accuracy in using modified Friedewald equation to calculate LDL from non-fast triglyceride: a pilot study. J Med Assoc Thai. 2009; 92(2):182-187. [PubMed: 19253792]

28. Pruessner JC, Kirschbaum C, Meinlschmid G, Hellhammer DH. Two formulas for computation of the area under the curve represent measures of total hormone concentration versus time-dependent change. Psychoneuroendocrinology. 2003; 28(7):916-931. [PubMed: 12892658]

29. Sadur CN, Eckel RH. Insulin stimulation of adipose tissue lipoprotein lipase. Use of the euglycemic clamp technique. J Clin Invest. 1982; 69(5):1119-1125. [PubMed: 7040473]

30. Yki-Jarvinen H, Taskinen MR, Koivisto VA, Nikkila EA. Response of adipose tissue lipoprotein lipase activity and serum lipoproteins to acute hyperinsulinaemia in man. Diabetologia. 1984; 27(3):364-369. [PubMed: 6389242]

31. Rashid S, Barrett PH, Uffelman KD, Watanabe T, Adeli K, Lewis GF. Lipolytically modified triglyceride-enriched HDLs are rapidly cleared from the circulation. Arterioscler Thromb Vasc Biol. 2002; 22(3):483-487. [PubMed: 11884294]

32. Lamarche B, Uffelman KD, Carpentier A, Cohn JS, Steiner G, Barrett PH, Lewis GF. Triglyceride enrichment of HDL enhances in vivo metabolic clearance of HDL apo A-I in healthy men. J Clin Invest. 1999; 103(8):1191-1199. [PubMed: 10207171]

33. Lund SS, Petersen M, Frandsen M, Smidt UM, Parving HH, Vaag AA, Jensen T. Sustained postprandial decrease in plasma levels of LDL cholesterol in patients with type-2 diabetes mellitus. Scand J Clin Lab Invest. 2008; 68(7):628-640. [PubMed: 19378436]

34. Schindhelm RK, Alssema M, Diamant M, Teerlink T, Dekker JM, Kok A, Kostense PJ, Nijpels G, Heine RJ, Scheffer PG. Comparison of two consecutive fat-rich and carbohydrate-rich meals on postprandial myeloperoxidase response in women with and without type 2 diabetes mellitus. Metabolism. 2008; 57(2):262-267. [PubMed: 18191058]

35. Metzig AM, Schwarzenberg SJ, Fox CK, Deering MM, Nathan BM, Kelly AS. Postprandial endothelial function, inflammation, and oxidative stress in obese children and adolescents. Obesity (Silver Spring). 2011; 19(6):1279-1283. [PubMed: 21233813]

36. Serin O, Konukoglu D, Firtina S, Mavis O. Serum oxidized low density lipoprotein, paraoxonase 1 and lipid peroxidation levels during oral glucose tolerance test. Horm Metab Res. 2007; 39(3): 207-211. [PubMed: 17373636]

37. Graner M, Kahri J, Nakano T, Sarna SJ, Nieminen MS, Syvanne M, Taskinen MR. Impact of postprandial lipaemia on low-density lipoprotein (LDL) size and oxidized LDL in patients with coronary artery disease. Eur J Clin Invest. 2006; 36(11):764-770. [PubMed: 17032343]

38. Sutherland WH, Walker RJ, de Jong SA, van Rij AM, Phillips V, Walker HL. Reduced postprandial serum paraoxonase activity after a meal rich in used cooking fat. Arterioscler Thromb Vasc Biol. 1999; 19(5):1340-1347. [PubMed: 10323788]

39. Leidy HJ, Apolzan JW, Mattes RD, Campbell WW. Food form and portion size affect postprandial appetite sensations and hormonal responses in healthy, nonobese, older adults. Obesity (Silver Spring). 2010; 18(2):293-299. [PubMed: 19629055]

40. Habas ME, Macdonald IA. Metabolic and cardiovascular responses to liquid and solid test meals. Br J Nutr. 1998; 79(3):241-247. [PubMed: 9577302] 


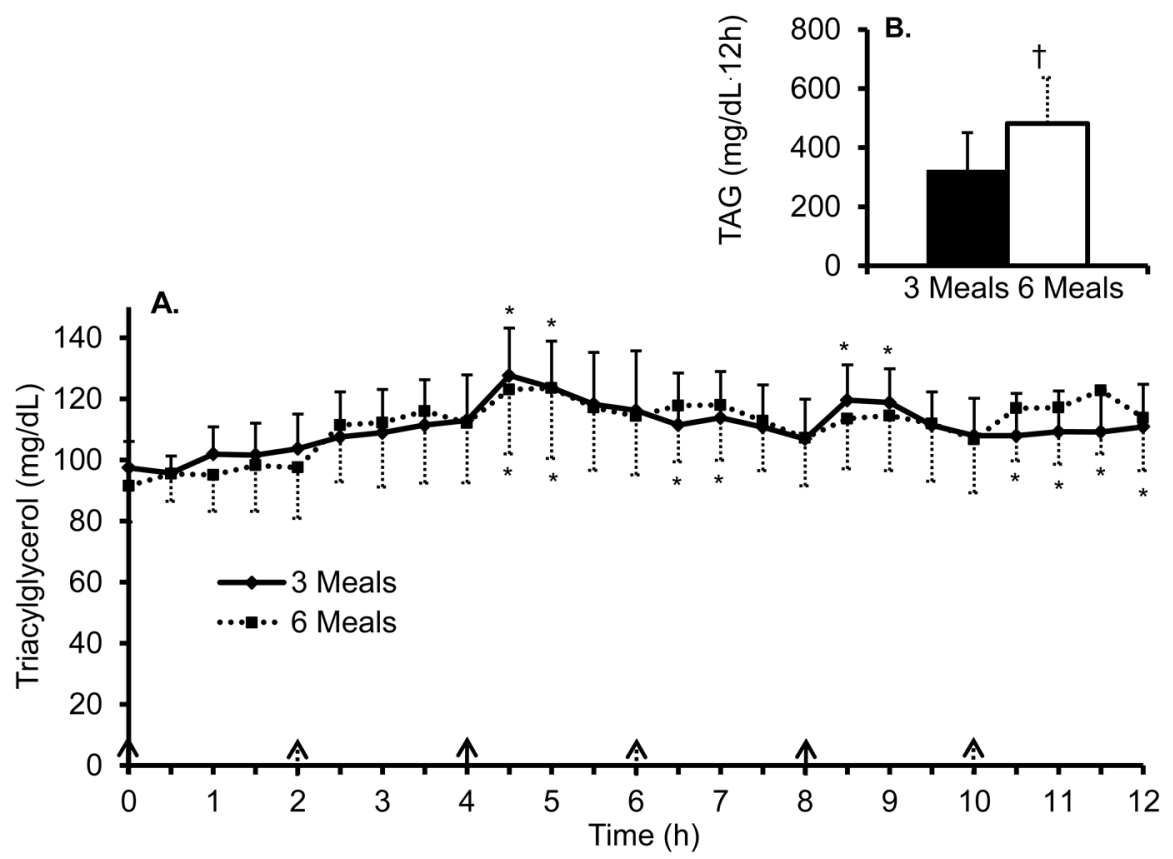

Figure 1. Postprandial triacylglycerol responses between three and six meals

A. Time course of postprandial triacylglycerol (TAG).

B. TAG incremental area under the curve.

All values are mean \pm s.e.m.

${ }^{*} P<0.05$ compared to baseline within condition.

Solid arrows represent meal given during both conditions and dashed arrows represent meal given during six meal condition. 


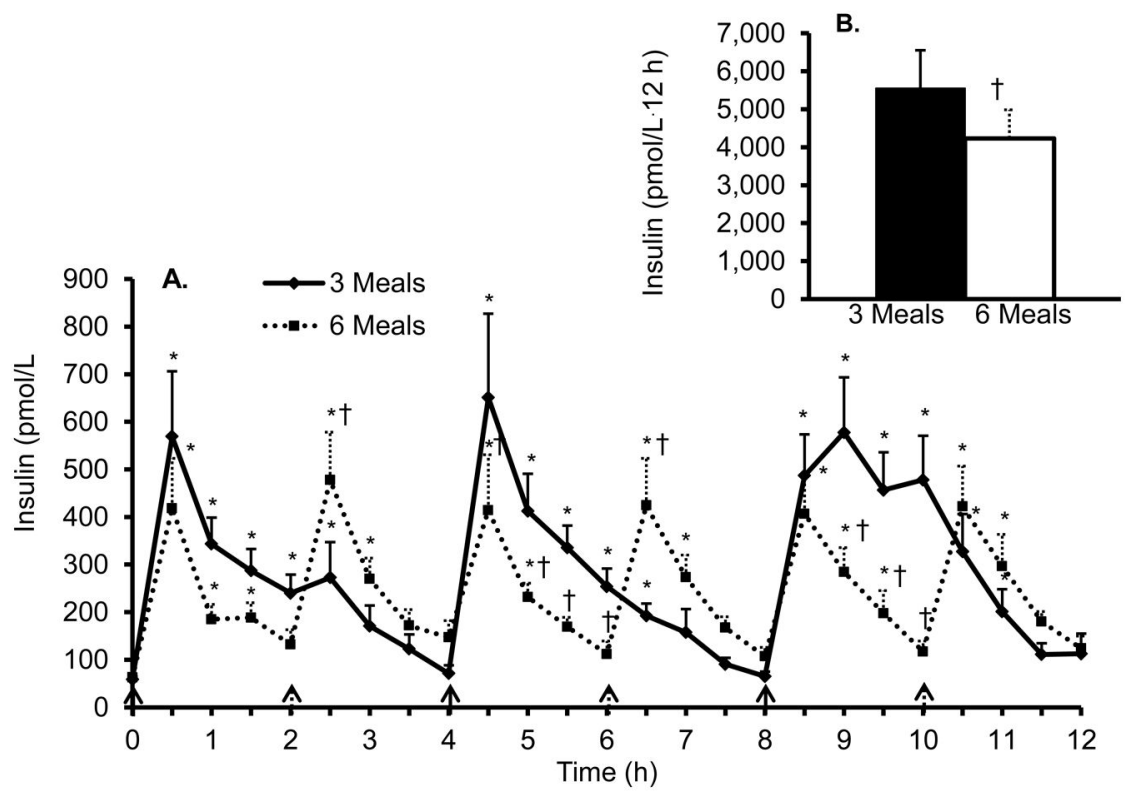

Figure 2. Postprandial insulin responses between three and six meals

A. Time course of postprandial insulin.

B. Insulin incremental area under the curve.

All values are mean \pm s.e.m.

${ }^{*} P<0.05$ compared to baseline within condition.

$\dagger P<0.05$ compared to three meal condition.

Solid arrows represent meal given during both conditions and dashed arrows represent meal given during six meal condition 


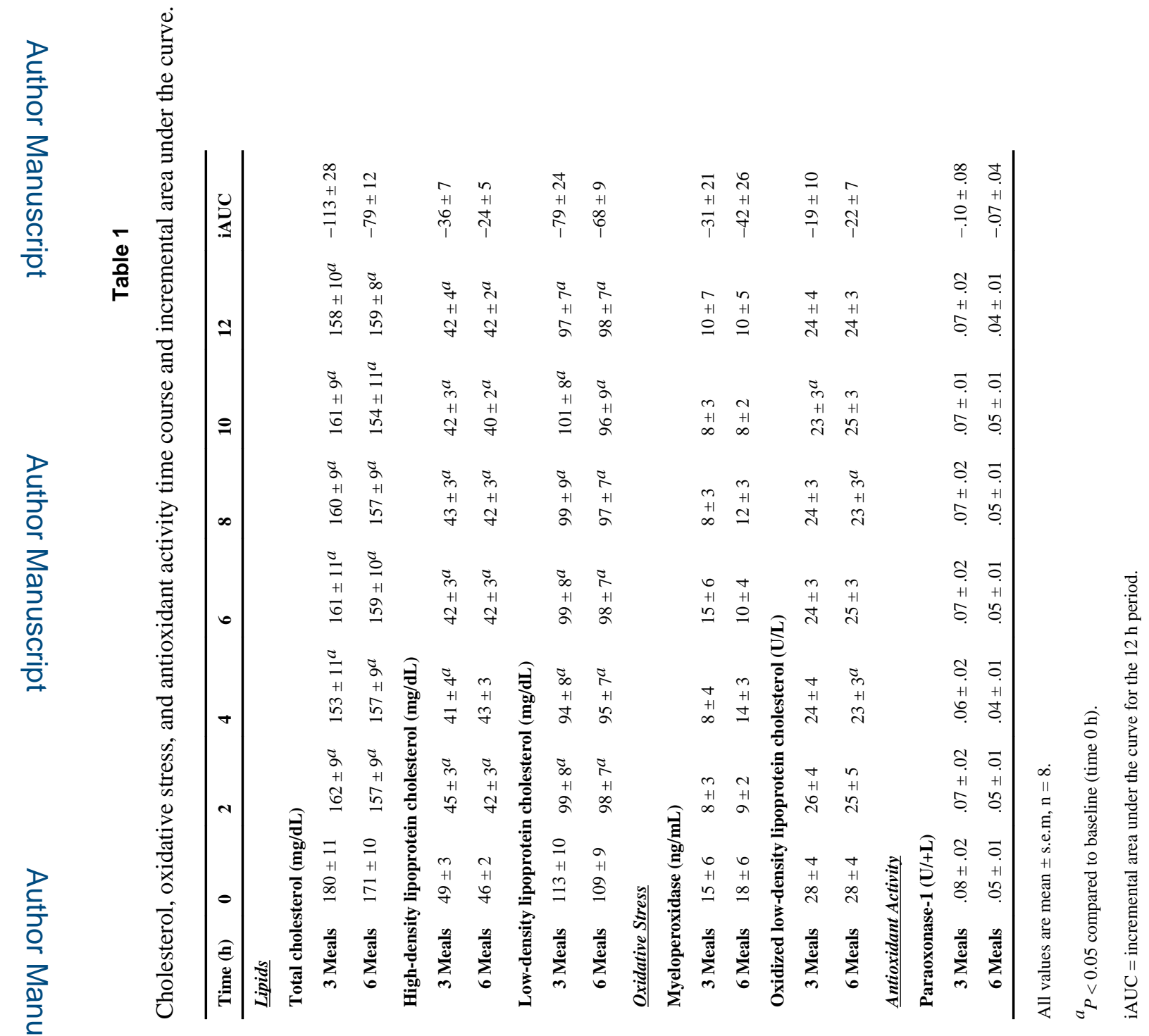

